Ethiopian Journal of Environmental Studies \& Management 7(1): 90 - 95, 2014

ISSN:1998-0507

doi: http://dx.doi.org/10.4314/ejesm.v7i1.11

Submitted: November 15, 2014

Accepted: February 4, 2014

\title{
A COMPARISON OF FORAGING SITE CHARACTERISTICS OF TWO AFRICAN RESIDENT INSECTIVOROUS BIRDS IN A BURNED HABITAT
}

\author{
${ }^{*}$ CHASKDA, A.A. ${ }^{1}$ AND MWANSAT, G.S. ${ }^{2}$ \\ ${ }^{1}$ A.P. Leventis Ornithological Research Institute, Department of Zoology, University of Jos, P.M.B. \\ 2084, Jos, Nigeria \\ ${ }^{2}$ Entomology and Parasitology Unit, Department of Zoology, University of Jos, P.M.B. 2084, Jos, \\ Nigeria
}

\begin{abstract}
Detailed investigation of the foraging site utilised by avian species may reveal the habitat factors important in their conservation. This study compared the foraging sites of the Sunlark, Galerida modesta and Familiar Chart, Cercomela familiaris (both African resident insectivorous birds) a week after fire engulfed about one third of the 300 ha of the Amurum Forest Reserve, Nigeria. Foraging sites were compared based on proxies of food availability (ant, grasshopper and other insect abundance) and vegetation structure. Data on food availability and vegetation structures were obtained by quadrate sampling while foraging spots were determined from four stratified transects each surveyed four times during the study. Food availability was not a significant predictor of foraging site characteristics between the two bird species. However of the nine vegetation variables measured, grass height and proportion of burned grass cover per foraging site significantly distinguished the foraging sites of the two bird species; Sunlark foraged more at sites with shorter grasses and high proportion of burned grass cover as compared to the Familiar Chat. The characteristics of the foraging sites observed might have implications on the foraging success of the birds in line with literature on the Influences of vegetation structure on avian foraging behaviour.
\end{abstract}

Key words: Foraging site, Insectivorous birds, Burn, Vegetation structure, Food availability

\section{Introduction}

Environmental disturbances such as caused by fire often modifies a habitat from its preimpact form (Turner et al., 2003); some of the detectable changes induced by fires include reduction in foraging habitat (Bowers et al., 1996; Martin and Morrison, 1999), reduction in vegetation cover such as seedlings, saplings, canopy, large trees (Smucker et al., 2005) and litter cover (Kutt and Woinarski, 2007) as well as reduction in species densities (Nelson et al., 2008). Such effects often produce a new set of challenges on survival and reproduction for organisms occupying such habitats. Most especially for organisms relying on habitat cues such as vegetation attributes to determine optimal foraging or breeding sites (Smith and Shugart, 1987; Marshall and Cooper, 2004; Hagar et al., 2007). Thus, the mode of response by organisms to such habitat changes may differ between species or even individuals. In the case of birds, at population levels, response could be numerical such as changes in

*Corresponding Author: Chaskda, A.A.

Email: chaskda@yahoo.com population density (as a result of emigration) or functional, such as changes in foraging behaviour (Lyons et al., 2008). Any change in foraging behaviour if it must be termed optimal however, should include ability to select areas providing the best resource either in terms of food availability or vegetation attributes that offers protection during foraging such as density of trees or shrubs (Kotler and Brown, 1988; Gunnarsson, 1996; Marshall and Cooper 2004; McNamara and Houston, 2008). A freshly burned habitat therefore provides the opportunity for comparison between bird species in their ability to quickly untangle optimal foraging sites in the face of sudden change in habitat structure. This is important considering that time since fire $(1-3$ years after burn) have been established to affect other aspects of avian ecology such as bird abundances (Smucker et al., 2005). However, under West African conditions, literature is rare in this regard partly due to the accidental nature of such conditions often providing little time for 
planning and data collection. This is perhaps the major reason why most previous studies in this direction are of an experimental nature often at sites where fires are deliberately set to achieve predetermined goals (Kutt and Woinarski, 2007; Powell, 2008) or are conducted several weeks, months or years after burning (Kreisel and Stein, 1999; Kutt and Woinarski, 2007; Powell, 2008). This study therefore compared the foraging sites of the Sunlark, Galerida modesta and Familiar Chart, Cercomela familiaris (both African resident insectivorous birds) one week after fire from an unknown source engulfed about one third of the 300 ha of the Amurum Forest Reserve, Nigeria. This was with a view to finding out whether foraging sites utilised by the two bird species in the burned areas differ in terms of food availability and vegetation structure.

\section{Methodology \\ Study Site}

The study was conducted during the late dry season; February - March 2006 within the Amurum Forest Reserve ( $9^{0} 53^{\prime} \mathrm{N}, 8^{0}$ 59'E) located $15 \mathrm{~km}$, northeast of Jos, Plateau State, North-Central Nigeria (Figure 1). The area spans 300 ha and is characterized by various habitat types, which include patches of gallery forest, scrub savannah, rocky outcrops and grassland. Temperatures may range between $15.5-30.5{ }^{\circ} \mathrm{C}$ (Payne 1998). The forest has been identified as an Important Bird Area (Ezealor, 2001). Part of the Reserve was engulfed with fire from an unknown source on the night of $15^{\text {th }}$ February, 2006 where about one third of the Reserve was burned down.

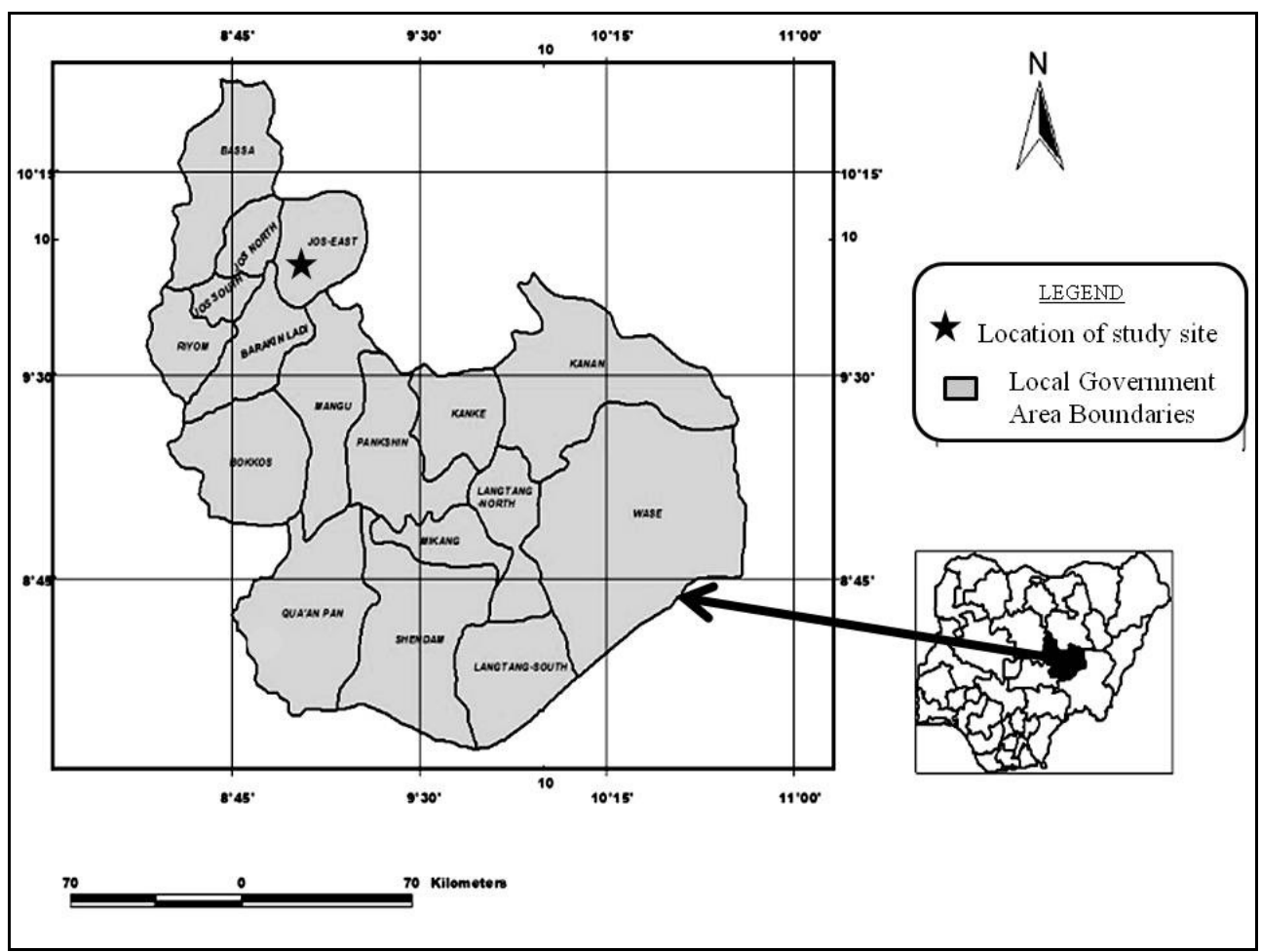

Figure 1: Map of Plateau State, Nigeria showing location of the study site

\section{Avian data collection}

Four transects of $1000 \mathrm{~m}$ lengths stratified $100 \mathrm{~m}$ apart in the burned area of the Reserve were surveyed for the candidate bird species beginning from 0630 - $1030 \mathrm{hrs}$ each day; two transects were surveyed per day. Each transect was eventually surveyed four times between $22^{\text {nd }}$ February (a week after the burning incident) to the $10^{\text {th }}$ of March, 2006. Bird identification was by the use of a binocular
(Trekka, $10 \times 42$ field of view) and bird identification guide (Sinclair and Ryan, 2003). Each individual of the candidate bird species encountered on transect was recorded as well as its activity.

Measurement of environmental variables at foraging sites

Environmental variables measured were classified into two viz; indicators of food abundance and vegetation structure. Indicators 
of food abundance include number of ants, number of grasshoppers and other flying insects. This generalisation is because specific insects constituting diet of the two insectivorous birds are not well established. However, a recent study in similar environment (The Jos Wildlife Park, Nigeria) had reported the insect Orders Hymenoptera (e.g. ants) and Orthopterans (e.g. grasshoppers) as constituting the top three insect Orders in the diet of insectivorous birds in the area (Turshak and Mwansat, 2011). Vegetation variables measured to characterise vegetation structure of foraging sites include: average shrub height, average grass height, grass cover, shrub cover, bare ground, burned grass, sprouting fresh grass, dry unburned grass and number of trees.

At each spot were individuals of the Familiar chat or Sunlark were sighted foraging, a 1 x $1 \mathrm{~m}$ quadrate was placed to enumerate number of ants. Furthermore, in a $10 \times 10 \mathrm{~m}$ quadrate, the following variables were quantified:

i. Average shrub height

ii. Average grass height

iii. Grass cover (Percentage)

iv. Shrub cover (percentage)

v. Bare ground (Percentage)

vi. Burned grass (Percentage)

vii. Sprouting fresh grass (percentage)

viii. Dry unburned grass (percentage)

ix. Number of trees

$\mathrm{x}$. Number of grasshoppers and other flying insects

Average shrub and grass height were each obtained from two randomly selected sites within the quadrate using a meter rule. However, grass cover, shrub cover, bare ground, burnt grass, sprouting fresh grass and dry un-burnt grass were estimated visually as the percentage of the $10 \times 10 \mathrm{~m}$ quadrate covered by each variable. Also, Number of grass hoppers and other flying insects were quantified using a sweep net; 30 sweeps were made twice in each $10 \times 10 \mathrm{~m}$ quadrate. Insects collected were sorted and enumerated into two categories; grasshoppers and other flying insects generally.

Statistical Analysis

All statistics was done using the software package SPSS (version 17.0, 2011). Data were statistically explored for normality and equality of variance using the 1-Sample Kolmogorov Smirnov test and Levene statistic; non parametric test was used where the assumptions of parametric test could not be satisfied. The Mann-Whitney U-test (a non parametric equivalent of the Independent Sample t-test) was used to compare differences in the foraging sites of the Sunlark and Familiar Chat. Variables compared where categorized into two; proxies of food availability (ant, grasshopper and other insect abundances) and vegetation structure (average shrub height, average grass height, grass cover, shrub cover, bare ground, burned grass, sprouting fresh grass, dry unburned grass and number of trees).

\section{Results}

A total of 43 individual birds were recorded across 35 foraging locations during the study. Of these, 25 birds (representing $58.1 \%$ ) were Sunlarks recorded at 18 different foraging spots. While 18 birds (i.e. $41.9 \%$ ) were foraging Familiar Chats observed at 17 different locations.

Foraging site characteristics: Food availability

In terms of food availability, foraging sites of the Sunlark were highly similar to that of the Familiar Chat as there was no significant differences observed between the foraging sites of the two study bird species either in terms of ant abundance (Mann-Whitney U-test, $\mathrm{Z}=$ $0.848, \mathrm{P}=0.397)$, grasshopper abundance $(\mathrm{Z}=$ $1.886, \mathrm{P}=0.059)$ or other flying insects $(\mathrm{Z}=$ $1.842, \mathrm{P}=0.065)$.

\section{Foraging site characteristics: vegetation structure}

Seven of the habitat variables measured as surrogates of vegetation structure (i.e. average shrub height, grass cover, shrub cover, bare ground, sprouting fresh grass, dry unburned grass and number of trees) did not significantly distinguish the foraging sites of the Sunlark from that of the Familiar Chat. However, grass height and burned grass cover per foraging site differed significantly between the two bird species studied (Table 1); Sunlark foraged more at sites with shorter grasses and high proportion of burned grass cover as compared to the familiar chat (Table 2). 
Table 1: Differences in foraging site vegetation structure between the Sunlark and Familiar Chat

\begin{tabular}{llll}
\hline Statistic & Habitat variables & $Z$ & $P$ \\
\hline Mann-Whitney U-test & Bare ground (\%) & 0.136 & 0.892 \\
& Sprouting fresh grass (\%) & 0.335 & 0.738 \\
& Shrub cover (\%) & 1.373 & 0.170 \\
& Shrub height (m) & 0.687 & 0.492 \\
& Dry grass cover (\%) & 1.746 & 0.081 \\
& Number of trees & 0.271 & 0.787 \\
& Grass height (m) & 2.555 & $0.011^{*}$ \\
& Burned grass cover (\%) & 2.947 & $0.003^{*}$ \\
\hline
\end{tabular}

$*$ = significant at 0.05 level

Table 2: Mean differences in foraging site characteristics between the Sunlark and the familiar Chat in burned areas of Amurum Forest Reserve between February - March, 2006.

\begin{tabular}{llcll}
\hline & \multicolumn{2}{c}{ Sunlark Foraging site } & \multicolumn{2}{c}{ Familiar chat Foraging site } \\
Habitat variables & $\mathrm{n}$ & Mean \pm S.E. & $\mathrm{n}$ & Mean \pm S.E. \\
\hline Number of ants & 18 & $18.44 \pm 6.91$ & 17 & $7.18 \pm 1.70$ \\
Bare ground $(\%)$ & 18 & $21.11 \pm 2.51$ & 17 & $20.59 \pm 2.70$ \\
Sprouting fresh grass $(\%)$ & 18 & $3.89 \pm 0.39$ & 17 & $4.82 \pm 0.84$ \\
Shrub cover $(\%)$ & 18 & $17.83 \pm 6.00$ & 17 & $7.06 \pm 1.44$ \\
Shrub height (m) & 18 & $1.022 \pm 0.13$ & 17 & $0.91 \pm 0.14$ \\
Number of Grasshoppers & 16 & $0.63 \pm 0.20$ & 16 & $0.19 \pm 0.10$ \\
Number of other flying insects & 18 & $0.11 \pm 0.07$ & 17 & $2.29 \pm 1.05$ \\
Dry grass cover $(\%)$ & 18 & $5.22 \pm 2.59$ & 17 & $45.88 \pm 10.46$ \\
Number of trees & 18 & $0.61 \pm 0.23$ & 17 & $0.59 \pm 0.29$ \\
Grass height $(\mathrm{m})$ & 18 & $0.12 \pm 0.01$ & 17 & $0.48 \pm 0.14$ \\
Burned grass cover $(\%)$ & 18 & $52.22 \pm 6.22$ & 17 & $26.47 \pm 7.21$ \\
\hline
\end{tabular}

\section{Discussion}

The foraging sites of the Sunlark and Familiar chat in a recently burned habitat were not distinguishable based on the proxies of food abundance explored in this study namely ant, grasshopper and other insect abundances. This was either because the two bird species have similar insect composition in their diet thus selecting areas rich in such required insect species or the specific insect species targeted by the species have not been effectively captured based on the techniques used in the study. Exploitation of similar food resources by different species of birds have been reported in previous studies (McLean et al., 1994; Khanna and Yadav, 2005).

Similarly, there was high correspondence in the vegetation structures characterising the foraging sites of the two bird species in terms of average shrub height, grass cover, shrub cover, bare ground, sprouting fresh grass, dry unburned grass and number of trees. However, average grass height and percentage cover of burned grasses per foraging site significantly distinguished the foraging sites of the two bird species; the Sunlark foraged more at sites with shorter grasses and with high proportion of burned grass cover as compared to the Familiar Chat. Vegetation structure has been previously reported to have influence on avian habitat selection (Kotler and Brown, 1988; Pribil and Picman, 1997; Whelan, 2001; Marshall and Cooper, 2004). In avian territoriality for example, certain vegetation structures such as leaf dispersion or foliage density could serve as cues in determining food resource rich areas (e.g. caterpillar density). This is possible in situations where food abundance and vegetation features correlate (Whelan, 1991; Marshall and Cooper, 2004). In this study, the shorter grasses and high proportion of burned grass cover characterising the foraging sites of the Sunlark might be cues that help it determine food resource rich areas as previously stated or a deliberate choice of sites where its preferred prey are most vulnerable to predation. Reduced vegetation cover as observed in this case could enhance predator visibility, prey encounter rates, predator manoeuvrability and less free space for prey to escape predation (Crowder and Cooper, 1982; Whelan 2001; Warfe and Barmuta, 2004; Janssen et al., 2007). However, such less vegetated foraging areas could also expose the bird quickly to its prey before any 
attack; particularly where target preys are flying insects thereby limiting foraging efficiency.

Conversely, tall grass cover and less burned grasses characterising the foraging sites of the Familiar Chat might be influenced by the birds consciousness of its own predators during foraging thus selection of such complex areas might provide a buffer against possible predators (Bowman and Harris, 1980; Martin and Roper, 1988; Gunnarsson, 1996; Warfe and Barmuta, 2004; Janssen et al., 2007).

\section{Conclusion}

Foraging sites of the Sunlark and Familiar Chat in burned habitat are not distinguishable based on the food resources measured in this study (ant, grasshopper and other flying insect abundance) as well as some of the vegetation variables characterising their foraging sites namely; average shrub height, grass cover, shrub cover, bare ground, sprouting fresh grass, dry unburned grass and number of trees. However, grass height and proportion of burned grass cover where significant predictors of the foraging sites of the two bird species studied. Influences of vegetation structure on avian foraging behaviour and on predator-prey relationship as reported in previous studies (Bowman and Harris, 1980; Crowder and Cooper, 1982; Martin and Roper, 1988; Gunnarsson, 1996; Whelan 2001; Warfe and Barmuta, 2004; Janssen et al., 2007) might have played a role in the selection of utilised foraging sites by the bird species. Also, utilisation of areas with high proportion of burned grasses as done by the Sunlark yet points to the beneficial effects of habitat burning on some fauna.

\section{References}

Bowers, R. K., Jr., Bowers, N. and Dunning Jr., J. B. (1996). A closer look: buff-breasted flycatcher. Birding, 28: 408-413.

Bowman, G.B. and Harris, L.D. (1980). Effect of spatial heterogeneity on ground-nest depredation. Journal of Wildlife Management, 44: 806-813.

Crowder, L.B. and Cooper, W.E. (1982). Habitat structural complexity and the interaction between bluegills and their prey. Ecology 63, 1802-1813.

Gunnarsson, B. (1996). Bird predation and vegetation structure affecting spruce- living arthropods in a temperate forest. Journal of Animal Ecology, 65: 389-397.

Hagar, J.C., Dugger, K.M. and Starkey, E.E. (2007). Arthropod prey of Wilson's Warblers in the understory of Douglas-fir forests. The Wilson Journal of Ornithology, 119: 533-546.

Janssen, A., Sabelis, M.W., Magalhaes, S., Montserrat, M. and Van der Hammen, T. (2007). Habitat structure affects intraguild predation. Ecology, 88: 27132719.

Khanna, D.R. and Yadav, P.R. (2005). Biology of birds. Discovery Publishing House, New Delhi, India. 27p.

Kotler, B.P. and Brown, J.S. (1988). Environmental heterogeneity and the coexistence of desert rodents. Annual Review of Ecology and Systematics, 19: 281-307.

Kreisel, K.J. and Stein, S.J. (1999). Bird use of burned and unburned coniferous forests during winter. Wilson Bulletin, 111(2), 243-250.

Kutt, A.S. and Woinarski, J.C.Z. (2007). The effects of grazing and fire on vegetation and the vertebrate assemblage in a tropical savanna woodland in northeastern Australia. Journal of Tropical Ecology 23, 95-106.

Marshall, M.R. and Cooper, R.J. (2004). Territory size of a migratory songbird in response to caterpillar density and foliage structure. Ecology 85, 432-445.

Martin, J. A. and Morrison, M.L. (1999). Distribution, abundance, and habitat characteristics of the buff-breasted flycatcher in Arizona. Condor, 101: 272281.

Martin, T.E. and Roper, J.J. (1988). Nest predation and nest-site selection of a western population of Hermit Thrush. Condor, 90: 51-57.

McLean I.G., Hölzer, C. and Sagar, P.M. (1994). Niche overlap and foraging ecology of island petroica species. NOTORNIS (Supplement) 41: 39-48.

McNamara, J.M. and Houston, A.I. (2008). Optimal annual routines: behaviour in the context of physiology and ecology. Philosophical Transactions of the Royal Society B: Biological Sciences 363, 301319. 
Nelson, N.L., Zavaleta, E.S. and Stuart Chapin III, F. (2008). Boreal fire effects on subsistence resources in Alaska and adjacent Canada. Ecosystems 11: 156171.

Payne, R.B. (1998). A new species of Firefinch (Lagonosticta sanguinodorsalis) from northern Nigeria and its association with the Jos Plateau Indigobird (Vidua maryae). Ibis, 140: 368-381.

Pribil, S. and Picman, J. (1997). The importance of using the proper methodology and spatial scale in the study of habitat selection by birds. Canadian Journal of Zoology, 75: 1835-1844.

Powell, A.F.L.A (2008). Responses of breeding birds in tallgrass prairie to fire and cattle grazing. Journal of Field Ornithology 79(1), 41-52.

Sinclair, I. and Ryan, P. (2003). Birds of Africa South of the Sahara. Struik Publishers, Cape Town. 48, 202-731 p.

Smith, T.M. and Shugart, H.H. (1987). Territory size variation in the ovenbird: the role of habitat structure. Ecology, 68: 695-704.
Smucker. K.M., Hutto, R.L. and Steele, B.M. (2005). Changes in bird abundance after wildfire: importance of fire severity and time since fire. Ecological Applications, 15(5): 1535-1549.

Turner, M.G., Collins, S.L., Lugo, A.E., Magnuson, J.J., Rupp, T.S. and Swanson, F.J. (2003). Disturbance dynamics and ecological response: the contribution of long-term ecological research. Bioscience 53:46-56.

Turshak, L.G. and Mwansat, G.S. (2011). Insect diet of some Afrotropical insectivorous passerines at the Jos Wildlife Park, Nigeria. Science World Journal, 6(4): 1-4.

Warfe, D.M. and Barmuta, L.A. (2004). Habitat structural complexity mediates the foraging success of multiple predator species. Oecologia, 141: 171-178.

Whelan, C.J. (2001). Foliage structure influences foraging of insectivorous forest birds: an experimental study. Ecology 82(1): 219-231. 